\title{
Natural history of fascia lata valves in the aortic and mitral positions
}

\author{
J.K. ROSS, J.C.R. LINCOLN, R. N. S A P S F O R D, a nd \\ J. W ISHEA R T \\ National Heart Hospital, London
}

\begin{abstract}
A total of 68 frame-mounted fascia lata valves were inserted in 59 patients between November 1969 and September 1970. The valves were all constructed by one or other of the authors with only minor variations in technique during the period of 10 months when this type of valve replacement was practised. All were mounted on cloth-covered metal frames whose geometry also remained substantially unaltered throughout the series. This report is concerned with the natural history of this type of valve substitute in the aortic and mitral positions. The evidence to date indicates that the frame-mounted fascia lata valve continues to function well in the aortic position for periods of more than two years, whereas in the mitral position the behaviour of the valve is unpredictable with a significant incidence of degenerative change and loss of function within one year of insertion.
\end{abstract}

Following the work of Senning (1967), whose experience with unmounted fascia lata aortic valve replacement was encouraging, and continuing the search for an autologous tissue valve substitute, the frame-mounted fascia lata valve was introduced in 1969 (Ionescu and Ross, 1969).

The early enthusiasm for this technique was surprising in view of previous work in the experimental field which showed that of all the possible autologous tissues theoretically able to withstand the stress of function as a valve, fascia lata showed possibly the greatest tendency to attract surface thrombus and to undergo degenerative change with fibrous replacement (Wilson, 1930 ; Moore and Shumacker, 1953 ; Brea, Allen, and Muller, 1965; Flege, Rossi, Auer, and Erenhaft, 1967; Gilbert, Mansour, Sanders, and Gravanis, 1968). In addition it relied on the premise that an inverted tricuspid semilunar valve supported on a rigid frame was a suitable valve substitute in the mitral position (Reid, 1970). Nevertheless, it seemed that with greater precision in design and construction these difficulties might be overcome, and the early clinical results were sufficiently encouraging to make this a reasonable possibility.

Between November 1969 and September 1970, 68 frame-mounted fascia lata valves were inserted in 59 patients, all of whom suffered from advanced acquired aortic and mitral valve disease. Of these,
40 were in the aortic and 28 in the mitral positionsô้

(Tables I and II).

The minimum follow-up at the time of review $\vec{O}$ was 15 months. Many patients have now been 3 followed up for over two years.

T A B L E I

40 FASCIA LATA VALVES IN AORTIC POSITION (All on Ionescu frames)

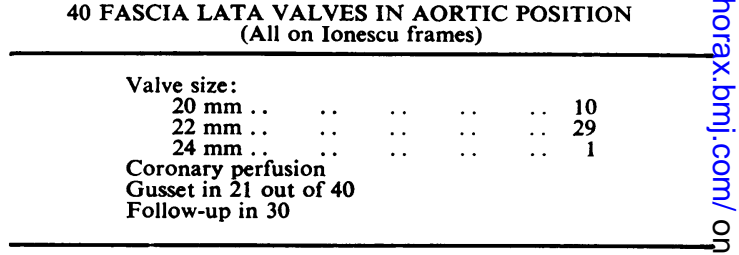

\section{T A B L E I I}

28 FASCIA LATA VALVES IN MITRAL POSITION (All on Ionescu frames)

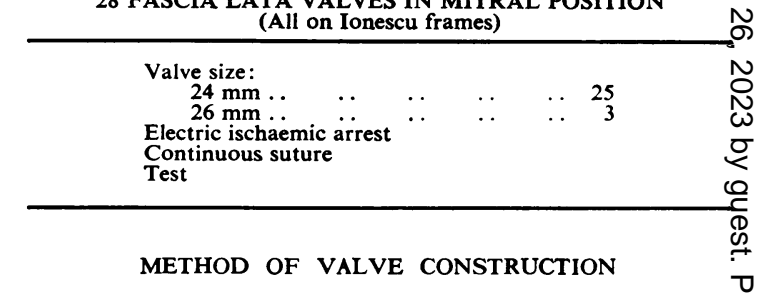

\section{METHOD OF VALVE CONSTRUCTION}

The method used to construct the valves was essen- $\stackrel{\vec{D}}{\vec{D}}$ tially that originally described by Ionescu and Ross $\frac{\rho}{9}$ (1969).

The fascia in each instance was cut to an oblong appropriate to the size of the frame to be used, and 
was then fashioned into a cylindrical shape by suturing the short edges of the fascia to each other on a graduated conical former. The fascia was then mounted on the frame with the fascial fibres running horizontally or at right angles to the axis of blood flow through the valve. In the early cases the suture line attaching fascia to fabric followed the scalloped upper rim of the frame, but with increasing experience the suture line was moved away from the hinge area of the cusps on to the upper surface of the skirt, and a trailing edge of fascia was left so that when the valve was inserted the greater part of the cloth sewing ring, or skirt, was covered. When used in the aortic position much of the sewing ring was trimmed off to reduce its bulk, but neither this minor variation in technique nor the revised position of the fasciato-fabric suture line altered the essential characteristics of the valve.

All the valves were inserted using standard normothermic cardiopulmonary bypass combined with continuous coronary perfusion when aortic valve replacement was undertaken. All the aortic valves were secured with multiple interrupted sutures as for a prosthetic valve, and in 21 instances it proved necessary to enlarge the aortic root with a gusset of crimped woven Dacron to accommodate the valve, mainly because of the prominence of the anterior prong of the frame. All the mitral valves were inserted during a period of elective ischaemic arrest using a continuous suture technique, the sutures being locked at four or more points round the sewing ring. Once in position the valve was tested for competence by introducing blood into the left ventricle by way of a left ventricular vent.

\section{T A B L E II I}

VALVE SIZES

\begin{tabular}{l|cccc}
\hline & $20 \mathrm{~mm}$ & $22 \mathrm{~mm}$ & $24 \mathrm{~mm}$ & $26 \mathrm{~mm}$ \\
\hline $\begin{array}{l}\text { Aortic } \\
\text { Mitral }\end{array}$ & 10 & 29 & 25 & $\overline{3}$ \\
\hline
\end{tabular}

The valve sizes are shown in Table III. It can be seen that the majority of those in the aortic position were mounted on $22 \mathrm{~mm}$ frames and in the mitral position on $24 \mathrm{~mm}$ frames.

\section{ANTICOAGULANTS}

Postoperatively all patients were anticoagulated for an arbitrary period of six to 12 weeks following which the anticoagulants were tailed off unless there was a special indication for their being continued.

\section{RESULTS}

FASCIA LATA VALVES IN THE AORTIC POSITION

Hospital mortality No patient died following isolated aortic valve replacement. There were two deaths following aortic and mitral valve replace- ment; thus 38 survivors are available for follow-up study (Fig. 1).

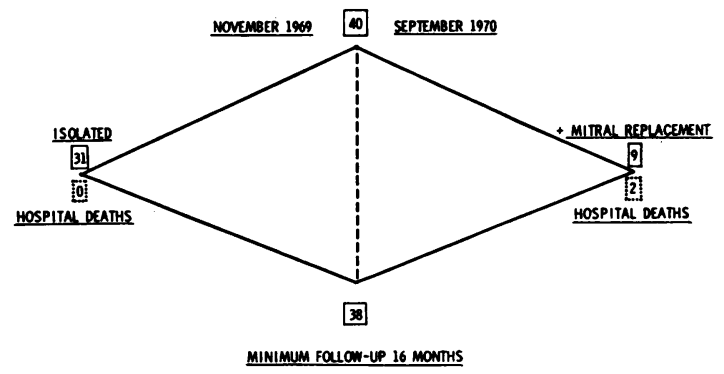

FIG. 1. Fascia lata valves in aortic position.

Clinical findings of the 31 who had isolated aortic fascia lata valve replacement, all but one has shown significant clinical improvement. This observation correlates well with the satisfactory auscultatory findings in the whole group which show a low incidence of diastolic murmurs (Table IV). A systolic ejection murmur is usual and an ejection click is common (Fig. 2). The one poor

\section{T A B L E IV}

FASCIA LATA VALVES IN AORTIC POSITION

\begin{tabular}{|c|c|c|c|c|c|}
\hline \multicolumn{6}{|c|}{ Diastolic murmurs: } \\
\hline Grade 0 & . & $\cdots$ & .. & . & .. \\
\hline & $\cdots$ & $\cdots$ & $\cdots$ & $\cdots$ & . \\
\hline & - & $\cdots$ & $\cdots$ & $\cdots$ & - \\
\hline & $\ddot{0}$ & 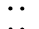 & $\cdots$ & $\cdots$ & $\cdots$ \\
\hline Early acu & $\ddot{\mathrm{p}}$ & livar & $\ddot{a k}$ & $\ddot{0}$ & 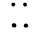 \\
\hline
\end{tabular}

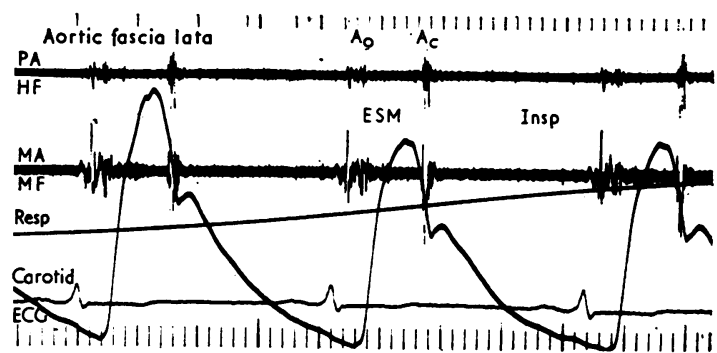

FIG. 2. Phonocardiogram of an aortic fascia lata valve. This shows an aortic ejection systolic murmur with an ejection click: $P A=$ pulmonary area; $H F=$ high frequency; $M A=$ mitral area; $M F=$ medium frequency; Resp=respiration; Carotid=carotid pulse; Ao=aortic opening snap or ejection click; Ac =aortic closure, aortic component of $S 2$; $E S M=$ ejection systolic murmur.

clinical result was in a 30 -year-old man who developed an early acute perivalvar leak. He had presented with severe isolated aortic regurgitation and at operation was found to have a typical 
'floppy' valve without calcification or evidence of past infection. When exposed at the second operation six and a half weeks after the first, the vaive itself looked satisfactory and the sewing ring was re-attached without difficulty. The tissues in the region of the dehiscence showed little evidence of attempted healing and none of infection. When re-investigated at 14 months, although the valve was shown to be competent by aortography, the catheter could not be passed retrogradely through the valve so that it is not known whether he has an important trans-valve gradient $(20 \mathrm{~mm}$ valve). This is a common difficulty when re-investigating this type of valve. During this procedure the patient suffered a left hemiplegia which is assumed to have been due to thrombus dislodged from the valve area. Although neurological recovery has been satisfactory, the heart continued to enlarge and there is some evidence that this may be due to coronary embolism. There has been no other example of cerebral embolism in the aortic series, also with transient neurological symptoms and signs.

Re-investigation Twelve patients have been reinvestigated by cardiac catheterization and angiography and the results are summarized (Table V).

\section{T A B LE V}

RE-INVESTIGATION OF 12 PATIENTS WITH FASCIA LATA VALVES IN AORTIC POSITION

$\begin{array}{cccccc}\text { 3 weeks } & & & & & \\ \text { 14-23 (av. 17) months } & \ldots & \ldots & \ldots & 9 \\ \text { 4 months } & \ldots & \ldots & \ldots & \ldots & 1 \\ \text { Trans-valve pressures: } & & & & \\ \text { No gradient } & \ldots & \ldots & \ldots & \ldots & 4 \\ \text { 5-15 mmHg } & \ldots & \ldots & \ldots & \ldots & 2 \\ \begin{array}{c}\text { Regurgitation: } \\ \text { Grade 0 }\end{array} & \ldots & \ldots & \ldots & \ldots & 8 \\ 1 & \ldots & \ldots & \ldots & \ldots & 3 \\ 2 & \ldots & \ldots & \ldots & \ldots & 1\end{array}$

The fact that the pressure gradient was measured in only half of these is a reflection of the difficulties, already mentioned, of passing a catheter through this type of valve. Two had systolic gradients at rest and aortography showed that the majority had competent valves.

Recently there has been an opportunity to examine one of these valves 19 months after insertion when mitral valve replacement became necessary for regurgitation aften open valvotomy at the first operation. The naked-eye appearance of the valve was entirely satisfactory, with persistence of the fascial striae and no evidence of surface thrombus, cusp thickening or loss of flexibility. A very small strand of fascia which had become partly detached from the free edge of one cusp was removed, and histologically this showed recognizable collagen bundles with nuclei between them (Fig. 3).

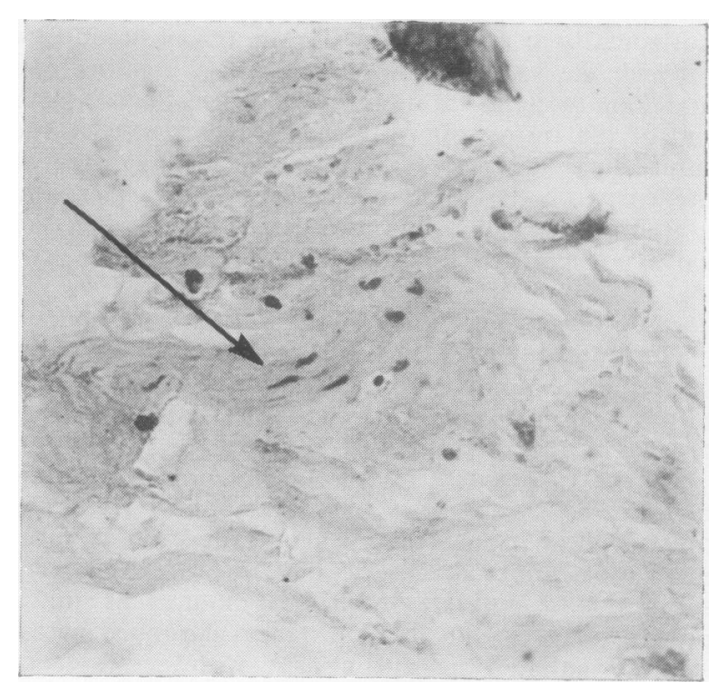

FIG. 3. Histological section of fascia lata removed from an aortic valve 19 months after insertion. Fibroblasts (arrowed) can be seen in the collagen fibres which are well preserved.

\section{FASCIA LATA VALVES IN THE MITRAL POSITION}

Hospital mortality The three patients who died in hospital after operation included one following isolated mitral valve replacement and the same two recorded in the aortic series following double valve replacement.

No hospital death was due to valve failure. Twenty-five patients with fascia lata valves in the mitral position are available for study (Fig. 4).

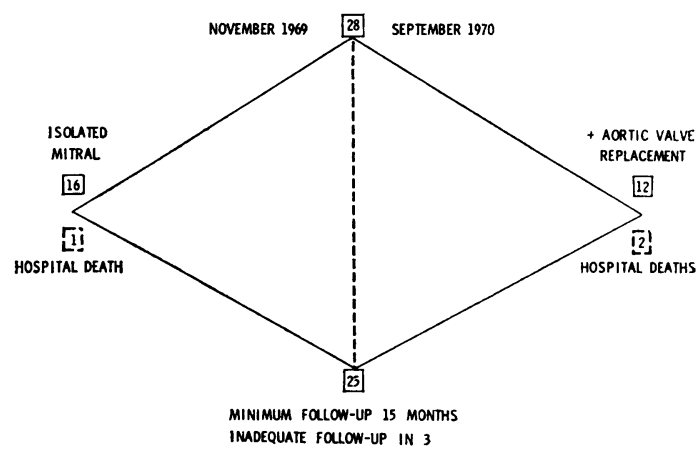

FIG. 4. Fascia lata valves in the mitral position.

Late mortality One patient died at re-operation seven and a half months after her initial aortic and 
mitral valve replacement when the leaking mitral valve had to be removed.

Clinical findings On clinical examination 13 $(50 \%)$ patients have systolic murmurs indicating significant valvar regurgitation and only four have no systolic murmur (Table VI; Fig. 5). In addition,

\section{T A B LE V I}

CLINICAL FEATURES OF PATIENTS WITH FASCIA LATA VALVES IN MITRAL POSITION

\begin{tabular}{cccccc}
\hline $\begin{array}{c}\text { Systolic murmur : } \\
\text { Grade } 0\end{array}$ & $\ldots$ & $\ldots$ & $\ldots$ & $\ldots$ & 4 \\
1 & $\ldots$ & $\ldots$ & $\ldots$ & $\ldots$ & 5 \\
2 & $\ldots$ & $\ldots$ & $\ldots$ & $\ldots$ & 11 \\
3 & $\ldots$ & $\ldots$ & $\ldots$ & $\ldots$ & 2 \\
Opening snap & $\ldots$ & $\ldots$ & $\ldots$ & $\ldots$ & 10 \\
Diastolic murmur & & $\ldots$ & $\ldots$ & $\ldots$ & 11 \\
\hline
\end{tabular}

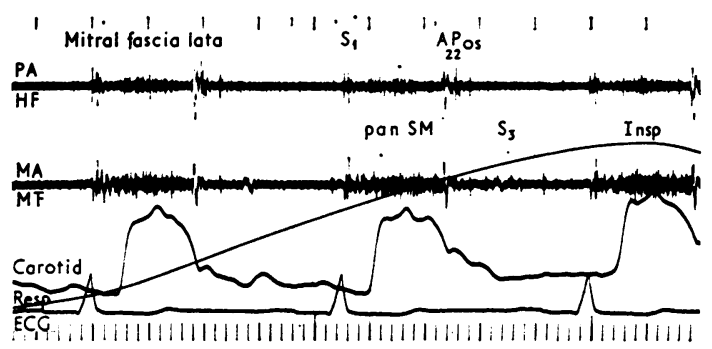

FIG. 5. Phonocardiogram of a mitral fascia lata valve. This shows a pansystolic murmur and an opening snap. Note sinus rhythm and absence of an atrial systolic murmur: $P A=$ pulmonary area; $H F=$ high frequency; $M A=$ mitral area; $M F=$ medium frequency; Resp=respiration; $S_{1}=$ first heart sound; $A_{2}=$ aortic component of $S_{2} ; P_{2}=$ pulmonary component of $S_{2} ; O S=$ opening snap; $S_{3}=$ third heart sound; pan $S M=$ pansystolic murmur.

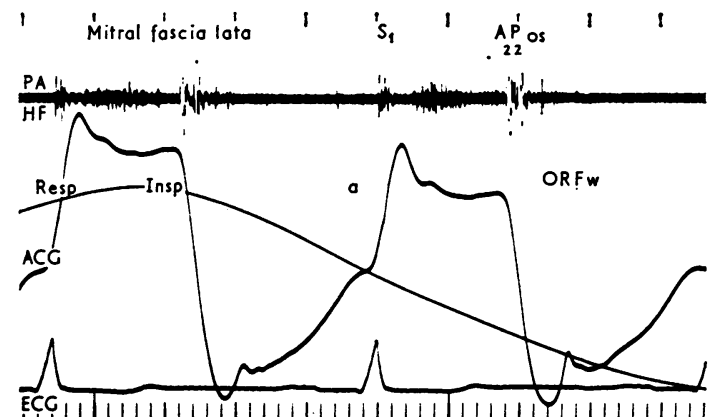

FIG. 6. Phonocardiogram of a mitral fascia lata valve. This shows an opening snap with an ' $O$ ' point identifying the opening snap as mitral in origin. The rapid filling wave is compatible with significant mitral incompetence: $P A=$ pulmonary area; $H F=$ high frequency; Resp=respiration; $A C G=$ apex cardiograms; Insp=inspiration; $S_{1}=$ first heart sound; $A_{2}=$ aortic component of $S_{2} ; P_{2}=$ pulmonary component of $S_{2}$; OS=opening snap; $a=$ ' $A$ ' wave; $O=o$ point mitral opening; $R F W=$ rapid filling wave. a diastolic murmur is present in 11 individuals and, of less significance, an opening snap may be heard in 10 (Fig. 6). In three the systolic murmur has become more intense, suggesting increasing regurgitation. The time lapse between operation and the first auscultatory signs of valve dysfunction is difficult to interpret because all but one who now have significant systolic murmurs were found to have developed them by the time of their first postoperative outpatient visit at four to six weeks. The single exception developed her murmur six months after operation and five months after a well-documented attack of early postoperative bacterial endocarditis. The murmur was, in fact, noted when she was re-admitted to hospital with infective hepatitis (Australia antigen) and it seems unlikely that the bacterial endocarditis was responsible for valve damage.

This patient represents the only incidence of bacterial endocarditis in either the aortic or the mitral group, and as she has fascia lata valves in both positions and neither has required replacement it is impossible to say which valve was affected. No patient with a fascia lata valve in the mitral position has had a systemic embolus.

Re-investigation Cardiac catheterization and angiography has been undertaken in $\mathbf{1 2}$ of the 25 survivors between six and 20 months after operation (Table VII). Mitral valve gradients of varying severity have been shown in seven of these. Three with diastolic gradients at rest of 7,6 and $5 \mathrm{mmHg}$ have no associated regurgitation, and one of these, whose gradient increases to $20 \mathrm{mmHg}$ on exercise, has a $26 \mathrm{~mm}$ valve, that is, the largest size used. Nine have been shown to have regurgitant valves on left ventricular angiography, and significantly impaired left ventricular function was demonstrated in three of those studied.

\section{T A B LE VII}

RE-INVESTIGATION 6 TO 20 MONTHS POSTOPERATIVELY OF 12 PATIENTS WITH FASCIA LATA VALVES IN MITRAL POSITION

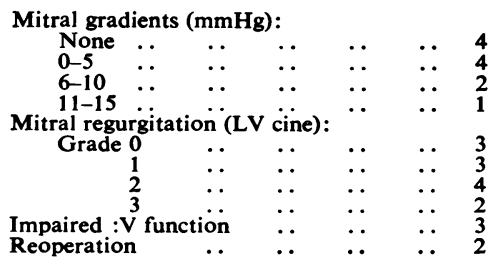

VALVES REMOVED To date, two leaking mitral valves have been removed, with one operative 
death and one successful replacement with a Starr-Edwards prosthesis.

The pattern of valve failure has proved to be essentially the same in each instance, two of the three cusps having become thickened, fibrotic, and retracted, and the third less severely affected (Fig. 7).

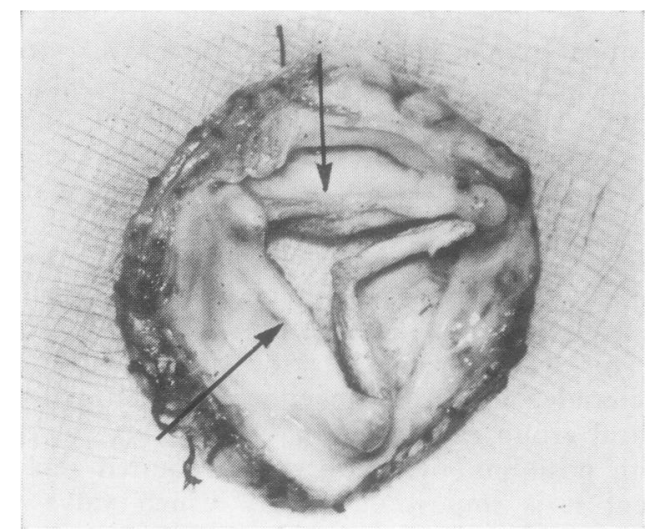

FIG. 7. Fascia lata mitral valve removed eight months after insertion. Two (arrowed) of the three cusps are shrunken and all are covered with a thick pseudoendothelium.

Histological examination has shown some preservation of fascial structure and cellularity with evidence of vascularization (Fig. 8). On the atrial or closing surface of the cusp an additional fibrous layer has developed or been deposited, and in the zone between the fascia and this added layer lie blood vessels and foreign body giant cell systems surrounding birefringent material.

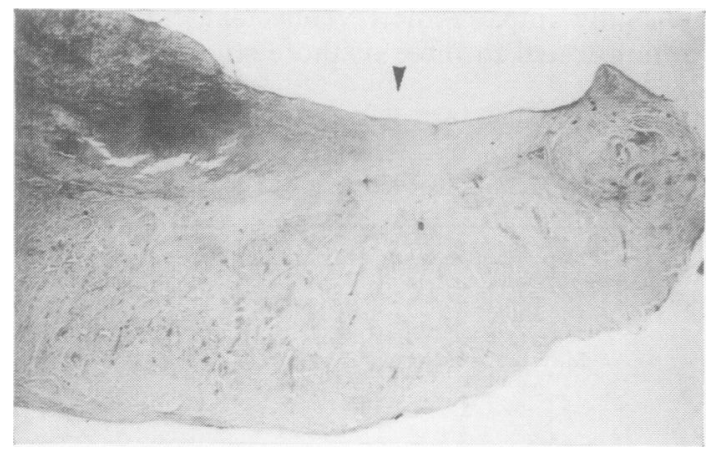

FIG. 8. Histological section of a fascia lata cusp from a mitral valve eight months after insertion. The ventricular surface (arrowed) is covered with a pseudoendothelium which could be organized thrombus. The collagen of the fascia lata is acellular.
The nature of the birefringent material is uncertain, but it is likely to be minute fragments of gauze swab which had become stuck to the surface of the fascia at the time it was removed from the thigh.

\section{DISCUSSION}

This study has shown that the natural history of a symmetrical three-cusp fascia lata valve mounted on a rigid frame is different in the aortic and mitral situations. In the mitral position the pattern of valve failure is the same as that reported by McEnany, Ross, and Yates (1972), but in the aortic position satisfactory valve function to the time limit of the study was found to be the rule.

It has long been appreciated that transplanted tissue will undergo fibrous degeneration if it is not subjected to physical stress appropriate to its structural characteristics (Krippaehne, Hunt, Jackson, and Dunphy, 1962). It could be argued, therefore, that for fascia lata the stress in the aortic valve situation is appropriate to its particular properties and that in the mitral situation it is not.

The anatomy of the aortic root and the left atrioventricular orifice, the flow and pressure characteristics, and the time relationships of these factors are all so different that it is likely to be a question of valve design, and the way that this influences the quality of the stress, that determines success or failure rather than the total severity of the stress in either situation.

It might be expected that the fascia lata cusp to be spared in the mitral position would be that lying in the subaortic region normally occupied by the anterior mitral cusp. Exact data on this point are lacking, but it is far from certain that this is a consistent finding.

The histological changes seen in the two mitral fascia lata valves removed showed proof of cusp thickening by a superimposed layer of fibrous tissue, reduction in the number of nuclei, and foreign body giant cell systems between the fascia and the extra surface layer. The decrease in numbers of viable fibroblasts with the passage of time has been the subject of an earlier communication (Lincoln et al., 1971) and the possible nature of the double refractile foreign body material has already been commented upon. At best, some of the fascia lata architecture can still be recognized: at worst, the picture tends to be one of slow degeneration with fibrous replacement and varying degrees of vascularization.

The single fragment of tissue removed from an 
aortic cusp at 19 months showed viable fibroblasts lying in collagen, but the specimen was too small for more observations to be possible. However, taken together with the satisfactory naked-eye appearance of the valve, it may be significant and serves to underline further the difference in natural history from its counterpart in the mitral position.

Another possibility is that degenerative change is going on in the aortic valves, but at a slower rate than in the mitral. To date there is no indication that this is so.

There was no evidence that the natural history of the valves was altered in any way by the use of long-term anticoagulants in the few instances when these were used.

It is not now our practice to use fascia lata as a valve substitute, and the reason for stopping was the incidence of valve failure in the mitral group; only later in the follow-up did the striking difference between the valves in the aortic and mitral positions become clear.

From the technical point of view the fashioning of the fascia lata valve added significantly to the operating time and involved a large wound in the thigh, an area we were glad was no longer exposed when aortic superseded femoral cannulation. However, in this series there was no incidence of serious infection in the thigh wound and although persistent accumulations of serous fluid sometimes required aspiration there was no longterm disability caused by the leg wound.

More important was the commitment to a particular valve size before institution of bypass and resection of the diseased valve could be carried out. Inevitably the disaster of having too large a valve for the annulus in question led to a tendency to make the valves a size smaller than was sometimes needed. The lack of variety of sizes shown in Table III bears out the trend towards producing a 'standard' aortic and mitral valve, and early attempts to assess aortic root size on the preoperative aortogram proved unreliable and this was abandoned.

The bulk of the cloth-covered frame and sewingskirt was also a problem in the aortic area and, although trimming the skirt helped significantly, the difficulty of the anterior prong of the valve (between the right and non-coronary cusps) remained. The large number of crimped Dacron gussets that had to be inserted to enlarge the aortic root reflects this difficulty, and this pro- cedure also added significantly to the operating time. By almost doubling the length of suture line in the aorta it also increased the number of needle holes in the aorta and therefore the possibility of bleeding, and bleeding through the gusset material itself was sometimes troublesome. In this series there was, however, no mortality directly attributable to the gusset and in particular no incidence of haemolytic anaemia.

\section{REFERENCES}

Brea, C. A. Jr., Allen, M. S. Jr., and Muller, W. H. Jr. (1965). Superior vena cava replacement with autogenous fascia. An experimental study. Amer. Surgn, 31, 610.

Flege, J. B., Rossi, N. P., Auer, J. E., and Erenhaft, J. L. (1967). Technique of mitral valve replacement with autologous fascia lata. J. thorac. cardiovasc. Surg., 54, 222.

Gilbert, J. W. Jr., Mansour, K., Sanders, S., and Gravanis, M. B. (1968). Experimental reconstruction of the tricuspid valve with autologous fascia lata. Arch. Surg., 97, 149.

Ionescu, M. I., and Ross, D. N. (1969). Heart-valve replacement with autologous fascia lata. Lancet, 2, 335.

Krippaehne, W. W., Hunt, T. K., Jackson, D. S., and Dunphy, J. E. (1962). Studies on the effect of stress on transplants of autologous and homologous connective tissue. Amer. J. Surg., 104, 267.

Lincoln, J. C. R., Riley, P. A., Revignas, A., Geens, M., Ross, D. N., and Ross, J. K. (1971). Viability of autologous fascia lata in heart valve replacements. Thorax, 26, 277.

McEnany, M. T., Ross, D. N., and Yates, A. K. (1972). Valve failure in seventy-two frame-supported autologous fascia lata mitral valves. J. thorac. cardiovasc. Surg., 63, 199.

Moore, T. C., and Shumacker, H. B. (1953). Unsuitability of transventricular autogenous slings for diminishing valvular insufficiency. Surgery, 33, 173.

Reid, K. G. (1970). Design criteria for a prosthetic orthotopic heart and mitral valve. Guy's Hosp. Rep., 119, 209.

Senning, A. (1967). Fascia lata replacement of aortic valves. $J$. thorac. cardiovasc. Surg., 54, 465.

Wilson, W. C. (1930). Studies in experimental mitral obstruction in relation to the surgical treatment of mitral stenosis. Brit. J. Surg., 18, 259.

\section{ADDENDUM}

Since this paper was prepared, the first example of fascia lata valve failure in the aortic group has occurred. This valve, in which one end of the right coronary cusp had torn away from its strut attachment, was successfully replaced with a Starr prosthesis. The time interval between the first operation and valve failure was two years. 